\title{
3. CREATIVITY OF CONTINUO PLAYERS AND INVESTMENT LAWYERS: A COMPARATIVE SKETCH
}

Flavia Marisi $^{259}$

\begin{abstract}
The Creative Problem Solving theory analyzes the main steps of a creative process: problem identification and delineation, information gathering, idea generation, its evaluation, refinement, implementation, and verification. Based on the findings of this theory, the present study aims at highlighting that not only artists and composers perform their tasks in a creative way, but also professionals doing jobs which are considered as not particularly creative. This study focuses in particular on continuo players and investment lawyers, stressing the often-overlooked creative elements of these jobs. The paper's conclusions highlight the individual and social returns of promoting creativity
\end{abstract}

Key words: figured bass, investment agreement, Creative Problem Solving, pedagogical implications

\section{Introduction}

Recent research highlighted that "Invention, innovation, originality, insight, illumination and imagination are core elements of the individual and societal progress along human history from ancient times till the modern society. These phenomena are often considered as indicators of creativity and talent in science, technology, business, arts, and music" (Leiki and Sriruman, 2017: 1).

This sentence puts into sharp relief that creativity does not belong only to those who work in the arts business, inventing and creating works of art thanks to their talent.

In effect, whereas, commonly speaking, the brilliance of the creative mind is highlighted, Howard Gardner stressed that "People are creative when they can solve problems, create products or raise issues in a domain in way that is initially novel but is eventually accepted in one or more cultural settings (...) [A] work is creative if it stands out at first in terms of its novelty but ultimately comes to be accepted within a domain" (Gardner 1999: 116-117). In this way, Gardner emphasizes that creativity is not a patrimony belonging only to geniuses working in the artistic field, but may rather characterize several experts of various sectors, and that creative works are implemented, evaluated and eventually accepted through social and historical processes.

Certain jobs are considered by definition as belonging to creative fields: painting pictures, making sculptures, composing music, choreographing ballets, writing poems and novels. Other jobs are seen as less creative or not creative at all, because according to the common opinion, they consist mainly in correctly implementing specific rules by means of Boolean choices. In this way, the whole work would be accomplished by the execution of rules, hence not by activities expressing creativity and personal choices. However, some scholars

\footnotetext{
259 Doctoral Candidate, University from Ghent, Belgium and LLM, Chinese University from Hong Kong, China, email: flavia.marisi@cuhk.edu.hk
} 
who focused their studies on creativity, highlighted that the latter includes several components:

(1) Important domain skills, including technical abilities, factual knowledge and talents specific to the domain (Amabile, 1996; Csikszentmihalyi, 1996, 1999); (2) Creativity skills, such as cognitive skills, relevant working styles or heuristics needed to explore new routes within a domain, and

(3) Task motivation that largely influences how a person approaches a set task (intrinsic and self-directed motivation are more effective than extrinsic motivations).

These skills and motivations can characterize also activities not usually included among the creative ones. Thorough-bass is a discipline in which the keyboard player interprets the figured-bass notation realizing the requested chords that are encoded therein. Arabic numerals, also termed signatures, are put by the composer over a continuo bass line, with each number indicating a certain interval. The continuo player shall interpret these numerals and 'translate' them into chords sutured through appropriate voice leading, realizing a harmonically and stylistically appropriate accompaniment (Christensen 2010).

This practice could be considered as characterized by a number of standardized aspects, since there are many rules to comply with. Indeed, some 17th and 18th centuries didactic works teaching thorough-bass emphasized the routinary elements of chord realization (Christensen 2010). However, the skills required to realize the thorough-bass, and these needed to compose music can be regarded as being complementary, which is also shown by the fact that in the Baroque era figured bass realization and composition were considered as having a close association. For these reasons, the practice of thorough-bass makes the boundaries between simple "translating numbers into notes" and compositional creativity quite vague (Christensen 2010)

In effect, in the period from 1600 to 1750 , termed by Hugo Riemann as "the age of figured bass" (Riemann 1904, I: vi) continuo players should be both analytical thinkers and music artists, understanding and have knowledge of how to combine harmonic rules with melodic inventiveness. However, in current music performance, crucial importance is given to pieces where most aspects have already been specified in detail by the composer, whereas lesser attention is paid to extemporary performance. In this scenario, the realization of a figured bass is usually not deemed to express and develop particular creativity.

To perform their job, lawyers must be able to assess the legal situation of a client, exploring the diverse options at hand, and establish a legal strategy by which the client can accomplish his/her objectives. Analytical rigor, logical thinking and a capacity to identify differences are needed to think like a lawyer, in addition to an ability to forcefully and reasonably argue either side of a problem (MacMillan 2015).

The following steps may be conducted by lawyers in various settings. A litigator might collect evidence regarding events that have already happened as a means of deciding if the client has any rights or duties relating to his/her adversary. A business lawyer could be presented with a contract and their advice 
requested regarding the rights and duties within the contract. In these two examples facts are fixed, and the lawyer must determine the legal effects of such facts. (Vandevelde 2011). In other cases, the procedure is inverted: this occurs if the legal effects are already known and the lawyer must establish the facts that could cause the desired consequence.

For instance, in the field of investment law it could be thought that the job of legal counsel, similarly to that of a continuo player, is not very creative: either if he/she works for an investor wishing to make an investment abroad, or for a state aiming at reaching an investment agreement with another state, or for either an investor or a state intending to sign an investment contract, the lawyer will be bound to respect and apply laws and regulations. This is true, in particular, in some jurisdictions where the roadmap seems to be almost completely set out, due to the role of binding or persuasive precedents.

For this reason, it is even more interesting to take a completely different perspective, considering whether, and if so to what extent, realizing a thoroughbass and working as a lawyer can be considered as ways to express one's own creativity. Although in studying the origins of discoveries and inventions we learn that creativity develops in a non-linear way over time (Sawyer, 2012), analyzing some thinkers' views on creativity, and verifying if they may be applied to the tasks performed by a continuo player and a lawyer representing a client who wishes to conclude an agreement can help us to shed a light on less known aspects of these jobs.

\section{Creative problem solving}

Creative Problem Solving (CPS) is a particular example of problem solving (Titus, 2000). It requires the transformation of information possessed by a subject through various methods, to achieve creative outcomes. It focuses on issues, for which the resolution involves creative expression through the development of relevant routes that are both innovative and suitable for doing the task in question (Amabile 1983). The main stages can be described as follows.

The first step can be termed "problem identification". Creative problem solvers' minds are curious and flexible: they can frequently anticipate issues and are most definitely able to identify them. This kind of persons can identify areas for improvement monitoring the way things are done, since they regard problems as opportunities for which they can seek to implement more effective solutions. They do not just observe their environment for changing patterns in opportunities for innovation, but also actively encourage innovation, which in turn leads to creative outcomes.

As the continuo player plays with other musicians, problem identification can have different points of departure: 1. Having selected the performing instruments, problem identification can be done by choosing the authors and the historical period to perform; 2. Having chosen the composers, or, more generally, the historical period to perform, problem identification can be done by selecting the music instruments; 3 . Having decided the time and venue of the 
performance, problem identification can be done by picking the performing instruments and the program based on the artistic inclinations and professional commitments of the potential performers, hence considering their needs, interests and objectives.

Therefore, in this phase, the continuo player shall respond to the questions what?, who?, where?, and when?. Also a lawyer, operating either in litigation or in the negotiations of agreements, and above all those concerning foreign direct investment, performs this first step investigating the features of the "problem" in terms of the parties' specific needs and interests and thus considering the following variables:

1) WHAT does the problem concern? What is at stake? Is there any way to resolve the issue?

2) WHO is involved? Are any other stakeholders than the concerned parties formally involved?

Is it possible for any additional parties to help in resolving the issue?

3) WHERE does the transaction take place? Is jurisdiction important? Can the location be changed?

4) WHEN must a resolution or conclusion regarding the dispute or transaction be reached? (Menkel-Meadow 2001).

The second step can be called "problem delineation". The problem solver must have a comprehensive understanding of the issue and carefully define it: whereas lack of time and effort spent in describing the issue could lead to an insufficient or false understanding (Couger 1995), by conducting thorough delineation, it is possible to avoid considering the problem as one-dimensional concentrating on only one aspect of it. Most of problems are multidimensional, and are caused by multiple factors, thus they necessitate a "set of solutions" (Couger 1995). This means that narrow perspectives could cause singular solutions that only effectively address one aspect of the issue.

In performing this step, the continuo player will listen to the sound of the specific instruments involved, verify the acoustics in the concert hall or in the recording studio, and make arrangements with the other musicians participating in the performance and with the recording engineer. The lawyer serving as legal counsel for an investor who wishes to make an investment abroad will take into consideration, among other aspects, the client's expectations, the substantive and procedural standards of coverage offered by different investment treaties, and their protection through investor-state arbitration.

The third step can be termed "information gathering". Information must be collected to offer a greater understanding of the issue and the relationship between variables. This enables the subject to identify what could cause problems (Fogler and LeBlanc 1995; Osborn 1963). Success is now dependent upon having a working knowledge of what information must be collected, and how and where to collect the information from. The collecting of information is an ongoing process, which facilitates more effective evaluation and the use of a subject's repertoire of problem-solving strategies. 
The continuo player will gather relevant information mainly from specific thorough-bass treatises, or general treatises including a section on continuo playing. He/she will take suggestions from the works originating from the same geographic area as the pieces he/she will perform, and coeval to them, paying special attention to the sections concerning the specific ensemble he/she will play with. The lawyer will identify the applicable sources of law, national, supranational and international rules, and the judicial and arbitral decisions applying them, paying special attention to those relating to the concerned countries (the investor's home state, and the state in which the investor will make an investment).

The fourth step can be called "idea generation". The creative thinker, after having studied what was done up to that moment, starts both the divergent and the convergent thinking, increasing the range of potential resolutions, assessing the positive and negative aspects of each potential solution and deciding which of them is the most suitable. The continuo player will hypothesize different kind of thorough-bass realization, from the simple realization of the needed harmonies through succession of chords above a bass, to a more complex structure, participating, as a concertante part, in imitations with the upper parts. Then he will choose the one which best fits to the piece, the sound of the performing voices and instruments, and the acoustic of the concert hall or the recording studio.The lawyer will posit different versions of the agreement, making comparisons with already signed agreements, highlighting their strengths and weaknesses, and always keeping his mind open to ideas and possibilities which can be proposed during the negotiation process.

The fifth step focuses on the idea evaluation, refinement, and implementation. Although judgment is not passed in the idea generation stage, the subject in charge of solving the issue must critically analyse the quality of projected ideas by assessing the positives and negatives ones, making changes to the solution in order to eradicate the negatives. Furthermore, the subject maintains control over the different aspects of the selected proposal, throughout the implementation stage, being ready to adjust them as required.

The continuo player will carefully listen to the whole sound of the piece, and the lawyer will then review the chosen proposal, and attempt to identify any remaining issues,

The sixth step concerns verification, and will typically be conducted within the socio-cultural setting that is instantiated in Csikszentmihalyi's concept of 'field'. A field consists of various experts working within the domain, who make up the social organization of the domain and decide its rules. Such experts are thus deemed to be gatekeepers, who verify the extent to which the proposal is culturally and historically relevant. One forms of value ascription regarding a subject's creativity, that is appraising what he does and realizes, is peer recognition.

Other important types of validation could include public recognition or the likelihood that the same professional is appointed again by the same client to a new job or a new concert, and that other clients know about him/her by word 
of mouth and appoint him/her trusting in the professional's credentials; the professional's affiliation with important institutions such as orchestras, universities, or leading legal firms; his/her presentations in international conferences and his/her publication of essays and articles in scientific journals.

Fields of specialists will assess the continuo player's and the lawyer's choices in addition to everyday citizens and consumers: legal experts, performers, music critics. All of them will assess and judge the creative product sanctioning its suitability and effectiveness, or vice-versa its inappropriateness and deficiency. A groundbreaking innovation in the negotiation of an agreement, as well as an artistically perfect continuo performance, may even represent a historic turning point in the relevant field, that could be taken as a model by many lawyers or musicians.

\section{Concluding remarks}

Drawing inspiration from CPS techniques identified by some researchers, the present study has examined the different steps usually made by professionals doing jobs which, as a rule, are considered as not particularly creative: the continuo player and the investment lawyer. The paper stresses that also these professionals perform their tasks in a creative way, doing all the steps characterizing CPS procedures.

Taking into consideration the pedagogical implications of CPS, it should be put in relief that developing one's own creativity is a fundamental strategy for growth, because it can help individuals and societies to keep pace with an ever-changing world. As creativity can be considered as a core characteristic of professionals working in all sectors, a very important task of all educational institutions is to train their students to develop their qualities and professionalism combining scientific rigor and creative flexibility in response to external stimuli.

\section{Bibliography}

1. Amabile Teresa M. (1996), Creativity in Context: Update to The Social Psychology of Creativity, Avalon Publishing, New York

2. Christensen Thomas (2010), Thoroughbass as music theory, in: Thomas Christensen, Robert Guerdoned, Giorgio Sanguinetti, Rudolf Lutz (eds.) (2010), Portamentos and Continuo Playing, Leuven University Press, Leuven, 9-42

3. Couger T. Daniel (1995), Creative Problem Solving and Opportunity Finding, Boyd \& Fraser Publishing, San Francisco

4. Csikszentmihalyi Mihaly (1996), Creativity: Flow and The Psychology of Discovery and Invention, HarperCollins Publishers, New York

5. Csikszentmihalyi Mihaly (1999), The Study of Creativity, in: R.J. Sternberg (ed.) (1999), Handbook of Creativity, Cambridge University Press, Cambridge

6. Fogler H. Scott, LeBlanc Steven E. (2008), Strategies for Creative Problem Solving, 2nd edition, Prentice Hall, Upper Saddle River

7. Gardner Howard (1999), Intelligence Reframed: Multiple Intelligences for the 21st Century, Basic Books, New York 
8. Leikin Roza and Sriraman Bharath (2017), Introduction to Interdisciplinary Perspectives to Creativity and Giftedness, in Roza Leikin and Bharath Sriraman (eds.) (2017), Creativity and Giftedness, Springer, Berlin

9. Leikin Roza and Sriraman Bharath (eds.) (2017), Creativity and Giftedness, Springer, Berlin

10. MacMillan Peter John (2015), Thinking Like an Expert Lawyer: Measuring Specialist Legal Expertise Through Think-Aloud Problem Solving and Verbal Protocol Analysis, dissertation, Faculty of Law, Bond University

11. Menkel-Meadow Carrie (2001), Aha? Is Creativity Possible in Legal Problem Solving and Teachable in Legal Education?, 6 Harv. Negot. L. Rev. 97144

12. Nuti Giulia (2016), Style in Keyboard Accompaniment in the Seventeenth and Eighteenth Centuries, Routledge, Oxon

13. Osborn Alex Faickney (1963). Applied imagination: Principles and procedures of creative thinking, 3rd edition, Charles Scribner's Sons, New York 14. Riemann Hugo (1904), Handbuch der Musikgeschichte, Breitkopf und Härtel, Leipzig

15. Sawyer R. Keith (2012), Explaining Creativity: The Science of Human Innovation, Oxford University Press, Oxford

16. Schauer Frederick (2009), Thinking Like a Lawyer: A New Introduction to Legal reasoning, Harvard University Press, Cambridge (MA)

17. Titus Philip A., Marketing and the Creative Problem-Solving Process, Journal of Marketing Education, 22(3), 225- 235.

18. Vandevelde Kenneth J. (2011), Thinking Like a Lawyer: An Introduction to Legal Reasoning, 2nd ed., Westview Press, Boulder 